\title{
Exposição à água contaminada: percepções e práticas em um bairro de Manaus, Brasil
}

\author{
Leandro Luiz Giatti, ${ }^{1,2}$ Natasha Lima da Silva Neves, ${ }^{2}$ \\ Giselle Nayara de Moraes Saraiva ${ }^{2}$ e Renata Ferraz de Toledo 3
}

Como citar Giatti LL, Neves NLS, Saraiva GNM, Toledo RF. Exposição à água contaminada: percepções e práticas em um bairro de Manaus, Brasil. Rev Panam Salud Publica. 2010;28(5):337-43.

RESUMO Objetivo. Investigar o modo de abastecimento de água e a percepção quanto aos problemas causados por essa água entre moradores de um bairro sem abastecimento público e instalado numa área anteriormente utilizada como depósito de lixo na Cidade de Manaus, Brasil.

Métodos. Foram realizadas 162 entrevistas semiestruturadas em domicilios do bairro, além de um grupo focal com professores de uma escola pública local, onde também houve uma reunião com moradores. Os instrumentos aplicados enfocaram a percepção e os modos de uso da água e o processo de exposição a contaminantes químicos pela água.

Resultados. Predominou entre a população o uso de água de poço sem qualquer tratamento. Essa água foi considerada como "boa" por $64,8 \%$ dos entrevistados. A maioria dos moradores $(88,3 \%)$ declarou saber da existência do lixão; desses, $77,6 \%$ afirmaram que o lixão causava problemas ao ambiente e à saúde. Contudo, análises qualitativas das respostas não demonstraram reconhecimento da contaminação por elementos químicos e nem de suas possiveis consequências. Em atividades com os professores, ficou claro que os mesmos conheciam parcialmente o problema, não realizando intervenções a esse respeito. Em reunião com os moradores foi identificada uma militância relativa ao problema dentro do bairro, mas que não extrapolava a localidade e não interagia com esferas governamentais.

Conclusões. O estudo identificou uma situação crítica de exposição que tende a se perpetuar em decorrência de percepçôes equivocadas e da falta de mobilização da sociedade. A disseminação de resultados junto a professores e moradores locais foi útil para empoderar os sujeitos da pesquisa.

Palavras-chave Abastecimento de água; exposição ambiental; poluição química da água; saúde ambiental; promoção da saúde; Brasil.

Na Amazônia, onde foram registradas as maiores taxas de crescimento urbano do Brasil nas últimas décadas, a população vem se concentrando sem dispor de serviços básicos adequados (1, 2). Especificamente, a Cidade de Manaus, ca-

1 Instituto Leônidas e Maria Deane (ILMD/Fiocruz), Departamento de Sociodiversidade, Manaus, AM, Brasil. Correspondência: lgiatti@usp.br

2 Universidade do Estado do Amazonas (UEA), Escola Superior de Ciências da Saúde (ESA), Manaus, AM, Brasil.

3 Faculdade de Educação da Universidade de São Paulo (FEUSP), São Paulo, SP, Brasil. pital do Estado do Amazonas, com população estimada de 1646602 habitantes no ano de 2007 (3), cresce rapidamente para regiões periféricas, caracterizando um fenômeno demográfico iniciado na década de 1970, tendo como principal precursor a política da Zona Franca e o consequente crescimento da indústria, da economia e da oferta de empregos (4).

Entre 1971 e 1986, um depósito de lixo que não contava com critérios técnicos de proteção ambiental existia em Manaus na área hoje ocupada pelo bairro
Novo Israel. Uma análise da qualidade da água de poços dos lençóis superficial e profundo nessa localidade e nas suas adjacências (5) mostrou que a água não era apropriada para consumo humano devido aos altos teores de contaminantes químicos. Tomando por base os achados de Rocha e Horbe (5) nos poços que abastecem a área, e considerando o manual de Boas Práticas de Abastecimento de Água do Ministério da Saúde (6), sabe-se que as substâncias encontradas na água dos poços no local incluíam alu- 
mínio, suspeito de ter relação com o mal de Alzheimer; antimônio, um possível carcinógeno, relacionado ao aumento do colesterol e à redução da glicose no sangue; arsênico, outro carcinógeno, que causa danos de pele, problemas no sistema circulatório e aumenta o risco de câncer de pele e de pulmão; cádmio, causador de lesões no fígado e disfunções renais; chumbo, que retarda o desenvolvimento físico e mental de crianças e causa problemas renais e aumento a pressão arterial em adultos, além de interferir no metabolismo da vitamina D, sendo também, possivelmente, carcinógeno; outro provável carcinógeno, o selênio, que causa queda de cabelos e unhas, problemas circulatórios, hepáticos e renais; e nitrito/nitrato, que causa a metemoglobinemia, levando à cianose.

Todavia, essa constatação não foi suficiente para encerrar o processo de exposição dos moradores locais a esses contaminantes. O objetivo desta pesquisa foi investigar o tipo de abastecimento de água e a percepção dos moradores de Novo Israel quanto aos problemas causados pela água utilizada no bairro. Essa investigação permitiu ainda identificar e disseminar os resultados como subsídio para atividades com grupos de professores e moradores do bairro.

\section{MATERIAL E MÉTODOS}

O bairro Novo Israel, localizado na zona norte da Cidade de Manaus, no Estado do Amazonas, surgiu em 1986, depois da desativação de um lixão que fora aterrado e posteriormente invadido por famílias de baixa renda (5). No momento do estudo, o bairro tinha uma população aproximada de 50000 habitantes. Porém, a área focal, universo deste estudo, compreendeu apenas a abrangência do antigo lixão. Essa área era atendida pela Unidade Básica de Saúde no 52 da Estratégia de Saúde da Família da Secretaria Municipal de Saúde, com 198 famílias cadastradas.

A metodologia deste estudo, de natureza descritiva, utilizou as abordagens quali e quantitativa. $\mathrm{O}$ estudo envolveu entrevistas semiestruturadas, executadas entre os meses de junho e julho de 2007. Nessa fase, foram incluídos todos os domicílios da área focal onde um morador maior de 18 anos estivesse presente nos dias das visitas, estando disposto a colaborar com o estudo. As entrevistas serviram para coletar infor- mações gerais do domicílio, percepções sobre o problema e informações específicas sobre idade e sexo de cada morador e doenças que houvessem ocorrido no período de 1 ano anterior à entrevista $(7,8)$. Os dados obtidos nas entrevistas foram cadastrados em planilha eletrônica. Variáveis quantitativas e qualitativas foram estudadas na forma de estatística descritiva por frequências e percentuais. As respostas abertas foram analisadas com base na análise de conteúdo (9), em que se procedeu à categorização buscando idéias coincidentes e divergentes. O questionário está disponível na forma de anexo 1 no final deste artigo.

De natureza qualitativa, foi utilizada também a técnica de grupo focal, que se baseia na tendência humana em formar opiniões na interação com outros indivíduos (10), e o painel integrado, instrumento participativo baseado em captar respostas de sujeitos para a identificação de conhecimentos prévios e a construção de novos conhecimentos (11). No grupo focal, a coleta de dados se deu a partir da discussão focada em tópicos específicos, propostos na forma de perguntas para debate pelo grupo. No painel, os participantes foram divididos em quatro grupos e convidados a refletir e responder questões sobre os problemas locais.

Foram realizadas duas reuniões com professores - aplicando grupo focal na segunda - e uma reunião com a comunidade - aplicando painéis integrados. Essas reuniões foram realizadas sob orientação de princípios da Promoção da Saúde, com direcionamento para reforço da ação comunitária, criação de ambientes favoráveis à saúde e elaboração e implementação de políticas públicas saudáveis (12). As informações obtidas com a aplicação das entrevistas, juntamente com dados bibliográficos referentes à contaminação local e possíveis consequências da exposição de seres humanos a essa contaminação, foram apresentadas previamente nas atividades com grupos, constituindo subsídios e embasando discussões. Assim, a sequência dos trabalhos caracterizou um processo de pesquisa socialmente responsável (13), em conformidade com as prerrogativas da Carta de Otawa para Promoção da Saúde (14). Não obstante, o desenho adotado constituiu uma proposta de contribuição das instituições de ensino e pesquisa de nível superior para a construção de conhecimentos, o empoderamento da sociedade e a participação no desenvolvimento de políticas intersetoriais relevantes de saúde pública (15).

As reuniões ocorreram na Escola Municipal Rubens Sverner, área focal do estudo, da seguinte maneira: no dia 16 de maio de 2008 realizou-se o primeiro contato, com apresentação de tema e objetivos do projeto, envolvendo os professores e a pedagoga da escola e os profissionais de saúde da Unidade Básica de Saúde. No dia 30 de maio de 2008 ocorreu a apresentação dos dados obtidos nas entrevistas e de informações precisas sobre o problema ambiental. Essa segunda reunião teve participação da pedagoga da escola e de 16 professores e profissionais de saúde (um administrador da Unidade de Saúde, uma enfermeira e um agente comunitário de saúde) e culminou com a realização de um grupo focal com 12 professores. Finalmente, no dia 6 de junho de 2008 ocorreu uma reunião com 30 integrantes da comunidade e profissionais da Unidade Básica de Saúde (uma enfermeira e um agente comunitário). Nesse momento foi aplicada a técnica de painel integrado dirigido especificamente aos moradores, os quais receberam convites, com 1 semana de antecedência, entregues por alunos da escola e por agentes comunitários de saúde. Durante todas as atividades de grupo também foi utilizada a observação participante. A observação participante é desenvolvida por meio da convivência e participação direta do pesquisador no universo de situações vivenciadas pelo grupo estudado, complementada pela anotação de dados relevantes e por sua interpretação, objetivando romper o monopólio do saber e da informação, estabelecendo relações entre problemas individuais e coletivos, funcionais e estruturais, como parte da busca por soluções coletivas (16). Além disso, os resultados qualitativos e quantitativos dos diversos instrumentos de pesquisa utilizados neste estudo foram analisados pelo processo de triangulação de métodos, o qual possibilita interpretar a realidade a partir de uma análise conjunta dos resultados obtidos por meio de diferentes técnicas de investigação (17).

Por parte das instituições de pesquisa e ensino superior envolvidas participaram do estudo pesquisadores, professor e alunos do curso de graduação em medicina. O projeto foi aprovado pelo Comitê de Ética em Pesquisa da Escola Superior de Ciências da Saúde da Universidade do Estado do Amazonas (protocolo $n^{\circ}$ 006/07 - CEP/ESA/UEA). 


\section{RESULTADOS}

Foram aplicadas entrevistas em 162 domicílios, nos quais residiam 837 pessoas. Houve predomínio de construções de alvenaria $(64,2 \%)$, sendo o restante de madeira ou madeira com alvenaria. As atividades em grupo realizadas na escola local envolveram 30 moradores locais, 16 professores da escola e três profissionais de saúde da Unidade Básica de Saúde local (um administrador, uma enfermeira e um agente comunitário de saúde).

Quanto à água utilizada para fins potáveis nos domicílios entrevistados, em sua maior parte provinha de poço profundo $(69,8 \%)$, seguido por água de cacimba (poço de lençol freático) $(19,8 \%)$. Verificou-se que em 74,1\% dos domicílios não havia nenhum tipo de tratamento para potabilização. A água utilizada para consumo foi avaliada como boa por $64,8 \%$ dos entrevistados e regular por $19,1 \%$. Dentre os métodos caseiros citados para tratamento estavam: filtragem $(13,0 \%)$, fervura $(6,8 \%)$ e uso de hipoclorito $(5,6 \%)$.

A procedência da água para cozinhar manteve-se com valores próximos aos de beber, diferentemente da água para higiene pessoal e do lar, que mostrou um aumento da utilização da água de cacimba. A maior parte das casas possuía sanitário em seu interior. O destino do esgoto era predominantemente fossa rudimentar $(41,4 \%)$ e a céu aberto $(34,5 \%)$. O lixo era coletado em $98,1 \%$ dos domicílios.

Quanto à percepção do problema ambiental, do total de respondentes, 88,3\% declararam conhecimento da existência prévia de um lixão no bairro. Desses, $77,6 \%$ reconheceram que esse fato poderia acarretar problemas ambientais e de saúde para a população local.

Dentre as respostas obtidas para as perguntas abertas sobre contaminação ambiental e saúde, foram recorrentes as citações de contaminação do solo, do ar e da água de lençóis subterrâneos. Contudo, ficou evidente que a população praticamente desconhecia a possibilidade de contaminação por elementos químicos, como metais pesados, capazes de desencadear uma variedade de doenças crônicas por meio da sistemática ingestão da água contaminada. Assim, predominou a convergência de respostas para uma relação do problema ambiental com doenças de quadro agudo, majo- ritariamente infecciosas. Apenas três respostas foram divergentes: "contaminação química do solo", "contaminação por mercúrio" e "verminoses, câncer, contaminação".

Dos entrevistados, 174 relataram problemas de saúde em algum morador da casa no período de 1 ano anterior às entrevistas, sendo os agravos mais comuns virose, diarreia e vômitos, ou seja, doenças infecciosas e seus sintomas. Em termos de doenças crônicas relevantes para os contaminantes ambientais em questão foram citados apenas três casos de hipertensão e um caso de cardiopatia.

Com relação às atividades em grupo, na primeira reunião realizada na escola foi possível identificar, por meio da observação participante, que o maior desafio prático para a promoção da saúde no local seria a mobilização da comunidade local, sendo interessante, portanto, abordar uma estratégia de incentivo à participação dos indivíduos que residiam no bairro. Os profissionais de saúde presentes nessa primeira reunião interagiram positivamente, sobretudo por estarem cientes e por vivenciarem a problemática local.

No segundo encontro na escola, uma detalhada apresentação demonstrando o problema da contaminação, bem como princípios da promoção da saúde, subsidiaram a realização do grupo focal, cujos resultados são apresentados na tabela 1 . A reunião com a comunidade envolvendo 30 moradores e agentes comunitários de saúde também se iniciou com uma apresentação de resultados da pesquisa e princípios da promoção da saúde. Posteriormente, teve uma boa participação dos moradores com a aplicação do painel integrado. As questões orientadoras dessa atividade objetivaram captar a visão dos participantes quanto ao problema, as possíveis soluções e a relação entre o consumo de água de má qualidade e os problemas de saúde passíveis de ocorrer.

Assim, os resultados dessa atividade, analisados conjuntamente com dados da observação participante, conforme preconiza a triangulação de métodos, mostraram que, apesar de haver ciência sobre a gravidade do problema, o forte condicionamento para usar água de poço dificultaria o uso de água encanada, caso fosse disponibilizada. Vale ainda ressaltar que a população entendia que uma resolução para o problema só seria possível se partisse de uma organização real da comunidade em prol do bem coletivo, embasada pelos dados e informações levados pelas instituições de pesquisa e ensino superior e regidas por uma representação forte, isto é, lideranças verdadeiramente comprometidas com o objetivo de encontrar soluções e levar adiante as ações necessárias para realizar mudanças.

\section{DISCUSSÃO}

Como diversos bairros periféricos de Manaus, Novo Israel surgiu de forma desordenada e sem infraestrutura, forçando a população local a perfurar cacimbas e poços para abastecimento de água (5). Sabe-se, no entanto, que a disposição inadequada de resíduos de origem urbana no solo caracteriza a permanência de contaminantes orgânicos e inorgânicos, a percolação no solo, a dispersão subterrânea de pluma (resultado do transporte de contaminantes dissolvidos em água subterrânea) e a contaminação da água de lençóis freáticos ou mesmo de aquíferos, um processo que pode se estender por décadas (5, 18-20).

Considera-se, porém, que a comprovação da relação de causa e efeito para exposições ambientais que possam desencadear manifestações crônicas em seres humanos demanda estudo específicos, em pesquisas frequentemente custosas e demoradas (21). Para Ravetz (22), os efeitos da exposição de humanos a poluentes ambientais se manifestam, geralmente, a longo prazo, sendo mascarados por outras causas. Soma-se a isso o fato de que a probabilidade de sinergia entre elementos nocivos e a potencialização de riscos é geralmente desconhecida, havendo grande dificuldade para comprovações por meio de uma ciência baseada em testes laboratoriais, que não incorpora outros fatores relevantes, como interesses corporativos, industriais, regulatórios ou profissionais que se posicionam contra o reconhecimento dos efeitos. No caso em estudo, até mesmo a necessidade de espaços para moradia em um mercado imobiliário profundamente desigual contribui para a ocupação da área contaminada e, consequentemente, para a exposição humana.

Diante de tais considerações, e também contando com as limitações do próprio sistema de saúde de identificar peculiaridades no perfil epidemiológico da população adstrita à área do antigo lixão, optamos por uma metodologia que objetiva o entendimento do processo 
TABELA 1. Resultados de aplicação de grupo focal com professores no bairro Novo Israel, Manaus (AM), Brasil, 2008

\begin{tabular}{|c|c|c|}
\hline Tema & Síntese das respostas e resultados das observações & Falas significativas \\
\hline $\begin{array}{l}\text { Contaminação da } \\
\text { água no dia-a-dia } \\
\text { da escola }\end{array}$ & $\begin{array}{l}\text { As falas dos professores faziam referência à apresentação preliminar por } \\
\text { parte dos pesquisadores, demonstrando como o método utilizado contribuiu } \\
\text { para as discussões. Assim, foram discutidas as relações de doenças } \\
\text { crônicas com exposição prolongada aos contaminantes, mostrando que esse } \\
\text { entendimento não era devidamente apropriado pelos participantes. Também } \\
\text { com referência à apresentação, relatos de dificuldade de aprendizado por } \\
\text { parte dos alunos foram apontados como tendo possível relação com a } \\
\text { exposição a elementos tóxicos. }\end{array}$ & $\begin{array}{l}\text { ". . conhecemos a história de como nasceu o bairro e a } \\
\text { gente especulava, mas não tínhamos nenhum dado } \\
\text { científico" (com relação ao problema). } \\
\text { ". . . eu sabia que estava contaminada; mas uma coisa é } \\
\text { saber que está contaminada, outra é saber o quanto está } \\
\text { contaminada! Foi assustador saber que o chumbo é } 29 \text { vezes } \\
\text { acima do aceitável e pior ainda a questão da direção do lençol } \\
\text { freático, que leva esse problema para os bairros vizinhos..." }\end{array}$ \\
\hline $\begin{array}{l}\text { Papel da } \\
\text { comunidade frente } \\
\text { ao problema }\end{array}$ & $\begin{array}{l}\text { Foi destacada a necessidade de conscientização da comunidade, assim } \\
\text { como organização da mesma em prol de reivindicações ao poder público. } \\
\text { Houve menção sobre a importância do trabalho de pesquisa e extensão por } \\
\text { parte das instituições de pesquisa e ensino superior, mas pouco se comentou } \\
\text { sobre o papel da escola nesse processo. }\end{array}$ & $\begin{array}{l}\text { "Os moradores durante muito tempo fizeram todos os } \\
\text { esforços para conseguir água, furaram poços, usam essa } \\
\text { água porque não tem outra, é preciso ficar esclarecido o } \\
\text { assunto, mas resolver isso é muito complicado." } \\
\text { "Eu julgo que a comunidade de Novo Israel tem que primeiro } \\
\text { se organizar. (. . .) se organizar para cobrar junto ao poder } \\
\text { público as melhorias em relação a essa problemática." }\end{array}$ \\
\hline $\begin{array}{l}\text { Como a escola } \\
\text { pode interferir na } \\
\text { busca de solução }\end{array}$ & $\begin{array}{l}\text { Opiniões fortemente divergentes, enquanto um grupo via a problemática } \\
\text { muito complexa para que a escola pudesse intervir, outro visualizava a } \\
\text { instituição de ensino como fundamental, sugerindo inclusive atividades mais } \\
\text { ativas como paralisações e manifestações para despertar o interesse público. } \\
\text { Falas contundentes afirmaram não ser possível a escola permanecer passiva } \\
\text { diante de problemas agora tão evidentes. Assim, um consenso surgiu nessa } \\
\text { discussão no sentido de a escola ser um mediador na busca de solução, a } \\
\text { qual deveria partir de abastecimento público de água. Enquanto mediador, a } \\
\text { escola deveria difundir conhecimento sobre o problema e mobilizar a } \\
\text { comunidade na busca por seus direitos. }\end{array}$ & $\begin{array}{l}\text { "No meu ponto de vista, é muito difícil isso de como a escola } \\
\text { poderia interferir. Eu acho que não haveria uma interferência, } \\
\text { mas sim você ser mediador dessas informações e levar ao } \\
\text { conhecimento de cada indivíduo que faz parte desse grupo } \\
\text { escolar." }\end{array}$ \\
\hline $\begin{array}{l}\text { Relação entre as } \\
\text { instituições de } \\
\text { pesquisa e ensino } \\
\text { superior, a } \\
\text { comunidade e a } \\
\text { escola }\end{array}$ & $\begin{array}{l}\text { Respostas enfatizando que a saúde não é área de atuação exclusiva de } \\
\text { profissionais da saúde. Destaque para conceitos de prevenção em saúde, } \\
\text { práticas saudáveis e intersetorialidade, visando a resolução do problema com } \\
\text { o envolvimento de universidade, escola, setor saúde, comunidade, poder } \\
\text { público. }\end{array}$ & $\begin{array}{l}\text { "Eu não vejo questão política, não está se tratando aqui de } \\
\text { uma questão política, mas sim de uma questão de ética, nós } \\
\text { termos esse conhecimento e não passarmos adiante. . ." } \\
\text { "Eu vejo essa relação (universidade - escola - comunidade) } \\
\text { como muito positiva porque ela não deixa de ser uma ação } \\
\text { política; não partidária, mas uma ação política social." }\end{array}$ \\
\hline $\begin{array}{l}\text { Subsídios que a } \\
\text { escola deseja } \\
\text { receber das } \\
\text { instituições de } \\
\text { pesquisa e ensino } \\
\text { superior }\end{array}$ & $\begin{array}{l}\text { De forma unânime, solicitaram a disponibilização de dados oficiais e } \\
\text { resultados da pesquisa realizada, os quais constariam como documentos de } \\
\text { suporte técnico para reivindicações a serem direcionadas ao poder público. }\end{array}$ & $\begin{array}{l}\text { "Nessa relação entre a universidade, a escola e a } \\
\text { comunidade, primeiramente que a universidade está fazendo } \\
\text { a parte dela. .." }\end{array}$ \\
\hline
\end{tabular}

de exposição, com seu referencial na implantação da Vigilância Ambiental em Saúde no Brasil, cujo sistema foi regulamentado em 2001. O nosso foco foi na exposição e nos processos sociais, econômicos e ambientais, em antecipação a modelos que historicamente concentram-se na vigilância de agravos (23).

O Ministério da Saúde do Brasil e, nos Estados Unidos, a Agência para Substâncias Tóxicas e Registro de Doenças (Agency for Toxic Substances and Disease Registry, ATSDR) $(24,25)$ adotam uma metodologia de análise de rotas de exposição no sentido de compreender as cadeias pelas quais contaminantes químicos podem atingir os humanos. Sob esse referencial, consideram como relevantes distintos aspectos que condicionam a exposição da população humana, tais como as práticas das pessoas expostas e o modo do ser humano ocupar e fazer uso do ambiente contaminado.

Com base nos resultados das presentes entrevistas, foi possível estabelecer uma rota de exposição $(24,25)$ da população de Novo Israel aos elementos químicos oriundos do lixão, que envolveu cinco pontos:

- fonte de contaminação: no caso, o depósito de resíduos sólidos, que tudo indica ser de origem predominante doméstica, mas sem informações precisas sobre outras classes de resíduos;

- compartimento ambiental e mecanismos de transporte: solo e água subterrânea;

- ponto de exposição: os próprios domicílios, por conta do uso doméstico da água;
- via de exposição: principalmente a ingestão, havendo também, possivelmente, em menor grau, absorção pela pele;

- população exposta: os moradores da área do antigo lixão e, segundo referência quanto à dispersão dos contaminantes via água subterrânea (5), também moradores de áreas adjacentes que podem estar utilizando essa água para suas necessidades diárias.

Considera-se ainda que a maioria das substâncias nocivas encontradas no local não pode ser retirada por tratamentos domiciliares, mesmo que devidamente e constantemente aplicados. Nem mesmo os tratamentos convencionais empregados em sistemas públicos de abastecimento seriam eficientes para a purifi- 
cação dessa água (6). Isso indica que a única solução para oferta de água de qualidade a essa população encontra-se no fornecimento emergencial de água encanada e tratada, captada de um manancial seguro. No caso de Manaus, o Rio Negro é utilizado para fornecer água para boa parte da Cidade. Porém, mesmo que a população de estudo tenha acesso a esse recurso hídrico via expansão de rede de adutoras, é necessário garantir a adesão dos moradores a um novo sistema de abastecimento, tendo em vista o fato de que esses consideraram a água disponível como boa, majoritariamente. Além disso, por ser a localidade ocupada por famílias de baixa renda, a pouca disponibilidade de recursos financeiros pode prejudicar ainda mais a adesão ao consumo de água de abastecimento público.

O processo de aplicação do grupo focal foi considerado bem-sucedido, pois deslocou a discussão para o nível coletivo, contribuindo para o empoderamento, ou seja, o fortalecimento dos indivíduos como sujeitos sociais, legitimando os professores como pessoas que interagem e são afetadas pelos problemas locais, além de atender as premissas da discussão e da formação de opiniões e atitudes por meio de interação com outros indivíduos, indicando um processo de mudanças e reafirmações (10).

Quanto à solução em termos de abastecimento público, os próprios moradores afirmaram não ser adequada a construção de poço local, uma prática recorrente nas periferias distantes de Manaus, como Novo Israel — nesses casos, um poço é instalado pela companhia de águas como solução alternativa em função da incapacidade de expandir as adutoras do sistema público de abastecimento. Mesmo com a apresentação preliminar, as falas dos participantes não demonstraram um perfeito entendimento da possibilidade de ocorrência de doenças crônicas com causas vinculadas ao consumo sistemático de água contaminada, prevalecendo a citação de doenças infecciosas de quadro agudo e seus sintomas. Do mesmo modo, a observação participante revelou em distintos momentos que os profissionais de saúde também não possuíam informações precisas sobre a epidemiologia de doenças crônicas dentre essa população. De fato, a compreensão de relações causais em pequenos grupos, como no caso da ex- posição sofrida pelos moradores de Novo Israel, é um grande desafio, sendo necessário o desenvolvimento de estudos epidemiológicos propriamente elaborados. Todavia, é de se considerar que, havendo maiores taxas de morbidade ou mortalidade por doenças crônicas nessa microrregião, é grande a possibilidade de essa informação ser diluída entre os indicadores epidemiológicos da cidade.

Embora sendo uma atividade isolada enquanto intervenção para empoderamento frente à problemática local, o encontro com os moradores na escola foi positivo por permitir uma discussão envolvendo a população exposta. Além disso, esse momento completou um circuito de interações que se iniciou no meio acadêmico, com a pesquisa, passando a ser discutido em nível local na escola, com envolvimento de professores, profissionais de saúde e moradores. $\mathrm{O}$ intuito do envolvimento de professores e da escola remeteu à necessidade de gerar autonomia local para lidar com a problemática estudada, sendo esses atores sociais formadores de opinião e ligados com questões da comunidade. Esse processo é fundamental para possibilitar o empoderamento e gerar a possibilidade de se criar uma escola promotora da saúde (26). Assim, o presente estudo se constituiu tanto em uma proposta interdisciplinar em termos de produção de conhecimento (27), como em proposta de intervenção, em que, com base no movimento de promoção da saúde, incentivase o empoderamento da população local e estimula-se a intersetorialidade para a construção de políticas públicas saudáveis (12).

No entanto, é preciso considerar que, em um sistema produtivo de bens e serviços de saúde, constituído por profissionais detentores do conhecimento científico e cidadãos imbuídos de senso comum, o elo mais fraco são os cidadãos (28). Assim, empoderar a população local quanto a uma situação crítica significa fomentar meios para a defesa de seus direitos coletivos e para a ruptura do atual quadro de inércia perante a um problema ambiental de significativa notoriedade.

Neste estudo, as técnicas participativas adotadas propiciaram interação e estimularam a intersetorialidade, tanto por envolver diferentes atores como por propiciar reflexão coletiva com relação aos elementos e ações necessárias para a re- solução dos problemas. De um modo geral, os subsídios oferecidos nas reuniões por conta das apresentações preliminares interferiram positivamente nas dinâmicas posteriores e, assim, estabeleceram as instituições de pesquisa e ensino superior, proponentes do projeto e das intervenções, como tendo um papel relevante frente à possibilidade de equacionamento de demandas locais. As instituições proponentes se colocaram como entidades produtoras e difusoras de conhecimento e, nessa missão, capazes de subsidiar e desvendar uma situação complexa em termos de exposição, indicadores de saúde e busca de soluções participativas. De fato, as evidências obtidas no processo permitem afirmar que os atores envolvidos nas atividades de grupo puderam compreender o papel das instituições de pesquisa e ensino superior, estando, daí em diante, munidos de argumentos produzidos por meio de pesquisa acadêmica, modalidade que frequentemente não é acessível a sujeitos de pesquisa (13) como os moradores ou mesmo os professores do bairro Novo Israel.

Conclui-se que há uma iminente necessidade de se oferecer água em quantidade e qualidade adequadas para abastecimento da população. Soma-se à gravidade da situação o fato de que a população não estava devidamente informada sobre os riscos e, do mesmo modo, não reconhecia os malefícios à saúde passíveis de ocorrência, o que contribuía para a permanência do próprio processo de exposição. Infere-se que a realização deste estudo foi uma oportunidade para a comunidade e a escola se apropriarem melhor da problemática por meio das atividades executadas. Além disso, constatou-se que a solução deve ir além do provimento do abastecimento de água, sendo necessário o constante emprego de métodos educativos para que os sujeitos passem efetivamente a utilizar uma nova e segura fonte de água.

Agradecimentos. Esta pesquisa recebeu auxílio em forma de bolsas de iniciação científica e custeio da Fundação de Amparo à Pesquisa do Estado do Amazonas (FAPEAM), por meio do Programa de Apoio a Iniciação Científica (PAIC) da Escola Superior de Ciências da Saúde da Universidade do Estado do Amazonas (ESA/UEA). 


\section{REFERÊNCIAS}

1. Becker BK. Geopolítica da Amazônia. Estud Av. 2005;19(53):71-86.

2. Instituto Brasileiro de Geografia e Estatística. Pesquisa nacional de saneamento básico. Rio de Janeiro: IBGE; 2002.

3. Instituto Brasileiro de Geografia e Estatística. Cidades@. 2009. Disponível em: www.ibge. gov.br/cidadesat/default.php. Acessado em 8 de janeiro de 2009.

4. Ribeiro Filho V. Mobilidade residencial em Manaus: Uma análise introdutória. Manaus: Editora da Universidade do Amazonas; 1999.

5. Rocha LCR, Horbe AMC. Contaminação provocada por um depósito de lixo no aqüífero Alter do Chão em Manaus - AM. Acta Amaz. 2006;36(3):307-12.

6. Brasil, Ministério da Saúde, Secretaria de Vigilância em Saúde. Boas práticas no abastecimento de água: procedimentos para minimização de riscos à saúde - Manual para os responsáveis pela vigilância e controle. Brasília: Ministério da Saúde/Secretaria de Vigilância em Saúde; 2006.

7. Heller L. Saneamento e Saúde. Brasília: OPAS/OMS; 1997.

8. Yin RK. Estudo de caso: planejamento e métodos. $3^{\mathrm{a}}$ ed. Porto Alegre: Bookman; 2005.

9. Bardin L. Análise de conteúdo. Lisboa: Edicões 70; 1977.

10. Iervolino SA, Pelicioni MCF. A utilização do grupo focal como metodologia qualitativa na promoção da saúde. Rev Esc Enf USP. 2001; 35(2):115-21

11. Nérici IG. Metodologia de ensino: uma introdução. São Paulo: Atlas; 1981.

12. Buss PM. Uma introdução ao conceito de Promoção da Saúde. Em: Czresnia D e Freitas CM, orgs. Promoção da saúde: conceitos, re- flexões, tendências. Rio de Janeiro: Editora Fiocruz; 2003. Pp. 15-38.

13. Peplow D, Augustine S. Community-directed risk assessment of mercury exposure from gold mining in Suriname. Rev Panam Salud Publica. 2007;22(3):202-10.

14. Ottawa Charter for Health Promotion. First International Conference on Health Promotion. Disponível em: www.who.int/ hpr/NPH/docs/ottawa_charter_hp.pdf. Acessado em 20 de março de 2009.

15. Muñoz M, Cabieses B. Universidades y promoción de la salud: ¿cómo alcanzar el punto de encuentro? Rev Panam Salud Publica. 2008;24(2):139-46.

16. Gajardo M. Pesquisa participante: propostas e projetos. Em: Brandão CR. Repensando a pesquisa participante. São Paulo: Brasiliense; 1985. Pp. 15-50.

17. Minayo MCS, Assis SG, Souza ER, orgs. Avaliação por triangulação de métodos: abordagem de programas sociais. Rio de Janeiro: Fiocruz; 2005.

18. Celere MS, Oliveira AS, Trevilato TMB, Segura-Muñoz SI. Metais pesados presentes no chorume coletado no aterro sanitário de Ribeirão Preto, São Paulo, Brasil, e sua relevância para saúde pública. Cad Saude Publica. 2007;23(4):939-47.

19. Oliveira S, Pasqual A. Avaliação de parâmetros indicadores de poluição por efluente líquido de um aterro sanitário. Eng Sanit Ambient. 2004;9(3):240-9.

20. Sissino CLS, Moreira JC. Avaliação da contaminação e poluição ambiental na área de influência do aterro controlado do Morro do Céu, Niterói, Brasil. Cad Saude Publica. 1996;12(4):515-23.
21. Câmara VM, Tambelini AT. Considerações sobre o uso da epidemiologia nos estudos em saúde ambiental. Rev Bras Epidemiol. 2003; 6(2):95-104.

22. Ravetz J. The post-normal science of precaution. Futures. 2004;36(3):347-57.

23. Barcellos C, Quitério LAD. Vigilância ambiental em saúde e sua implantação no Sistema Único de Saúde. Rev Saude Publica. 2006; 40(1):170-7.

24. Ministério da Saúde. Programa nacional de vigilância em saúde de populações expostas a solo contaminado. Brasília: Ministério da Saúde; 2006. Disponível em: portal.saude. gov.br/SAUDE/visualizar_texto.cfm?idtxt= 23567. Acessado em 17 de janeiro de 2009.

25. Agency for Toxic Substances and Disease Registry. Evaluación de riesgos en salud por la exposición a residuos peligrosos [manual]. Atlanta: ATSDR; 1992. Disponível em: www. bvsde.paho.org/bvsacd/eco/030079/03007900.pdf. Acessado em 2 de abril de 2009.

26. Pelicioni MCF. Educação em saúde e educação ambiental: estratégias de construção da escola promotora da saúde [tese]. São Paulo: Universidade de São Paulo; 2000.

27. Possas CA. Social ecosystem health: confronting the complexity and emergence of infectious diseases. Cad Saude Publica. 2001; 17(1):31-41.

28. Lefèvre F, Lefèvre AMC. Saúde, empoderamento e triangulação. Saúde Soc. 2004;13(2): $32-8$.

Manuscrito recebido em 24 de junho de 2009. Aceito em versão revisada em 10 de junho de 2010.
ABSTRACT

Exposure to contaminated water: perceptions and practices in a neighborhood in the city of Manaus, Brazil

Key words
Objective. To investigate the modes of water supply and the perception concerning the problems caused by this water among residents of a neighborhood without public supply of water, settled in an area previously used as a garbage dump in the city of Manaus, Brazil.

Methods. One hundred and sixty-two semi-structured household interviews were conducted. In addition, a focal group with teachers from a local public school and a meeting with residents were held. The instruments employed focused on the perception and modes of water use and on the process of exposure to chemical contaminants through water.

Results. Untreated well water was used by most families. This water was considered to be "good" by $64.8 \%$ of the individuals interviewed. Most residents $(88.3 \%)$ declared knowledge about the garbage dump. Of these, $77.6 \%$ stated that the garbage dump caused health and environmental problems. However, qualitative analysis of the responses revealed that the residents were not aware of contamination by chemical elements or of the consequences of such contamination. The activities carried out with teachers revealed that they were partially aware of the problem, but did not design interventions to address the issue. In a meeting with neighborhood residents, the presence of social activism concerning the problem was identified, but it did not extend beyond the neighborhood or reach governmental spheres.

Conclusions. The study identified a situation of critical exposure that tends to be maintained as a result of misperceptions and lack of social mobilization. The dissemination of research results to teachers and residents was useful to empower subjects.

Water supply; environment exposure; water pollution, chemical; environmental health; health promotion; Brazil. 
ANEXO 1. Questionário sobre modo de abastecimento de água e percepção quanto aos problemas causados pela água entre moradores do Bairro de Nova Israel, Manaus (AM), Brasil, 2008

\section{UEA - UNIVERSIDADE DO ESTADO DO AMAZONAS ESCOLA SUPERIOR DE CI NCIAS DA SAÚDE}

Abastecimento de ÁGUA E PROMoção da SaÚde NO BAIRRO DE NOVO ISRAEL — MANAUS — AM

Nome:

Endereço:

Cód.:

1) DOMicílio, FAMíLIA E SAÚDE:

Número de cômodos na residência? Quantas pessoas residem neste domicílio?

Tipo de construção da residência:

Tipo de piso: $\quad$ Chão batido $\square$ Madeira $\square$

Alvenaria $\square$

Madeira e alvenaria

Pau a pique

Algum morador deste domicílio teve algum problema de saúde no período de junho de 2006 a maio de 2007? (Descrever)

Nome

$$
\text { Idade Sexo Descrição do problema de saúde }
$$

1)

2)

3)

4)

5)

6)

7)

8)

2) Saneamento e Ambiente

Procedência da água para beber?

Poço (cacimbão) $\square \quad$ Água encanada

Poço profundo

Nascente $\square$

Igarapé

Chuva $\square$

O que você acha da qualidade desta água utilizada para beber?

Você realiza algum tratamento para a água de beber?

Fervura $\square \quad$ Filtragem $\square \quad$ Decantação $\square \quad$ Hipoclorito/água sanitária $\square \quad$ Nenhum

Procedência da água para cozinhar?

Poço (cacimbão) $\square \quad$ Água encanada $\square \quad$ Poço profundo $\square \quad$ Nascente $\square \quad$ Igarapé $\square \quad$ Chuva $\square$

Procedência da água para higiene pessoal e do lar?

Poço (cacimbão) $\square \quad$ Água encanada $\square \quad$ Poço profundo $\square \quad$ Nascente $\square \quad$ Igarapé $\square \quad$ Chuva $\square$

Onde fica a privada de sua casa?

Dentro do domicílio

Fora do domicílio

Não há

Qual o destino dos esgotos

Igarapé $\square \quad$ Fossa rudimentar $\square \quad$ Fossa séptica $\square \quad$ Rede pública $\square \quad$ Céu aberto $\square$

Qual o destino do lixo produzido no domićlío?

Coletado $\square \quad$ Joga no entorno do domicilio $\square \quad$ Enterra $\square \quad$ Igarapé $\square \quad$ Queima $\square \quad$ Outro $\square$.

Você sabe o que havia aqui antes de se formar o bairro?

Sim $\square \quad$ Não $\square \quad$ Se a resposta for sim, explicar:

Você sabe o que é um lixão?

Sim $\square \quad$ Não $\square \quad$ Se a resposta for sim, explicar:

O fato de ter existido um lixão antes de formar o bairro causa algum problema ao ambiente ou a saúde dos moradores locais?

Sim $\square \quad$ Não $\square \quad$ Se a resposta for sim, explicar: 